\title{
Prediction of height and body mass index based on body segments. Use of Gauld's equations in an Argentine sample
}

\author{
Rosario Ramos Mejía, M.D., ${ }^{a}$ Silvia Caino, M.D., ${ }^{a}$ Paula Adamo, Anthropometrist, ${ }^{a}$ \\ Virginia Fano, M.D., ${ }^{a}$ and Diana Kelmansky, M.D. ${ }^{b}$
}

\section{ABSTRACT}

When height cannot be measured or does not account for actual bone growth in children, due to their condition, it may be estimated using equations based on body segments.

Objectives. 1. To compare observed height $(\mathrm{OH})$ and predicted height $(\mathrm{PH})$ based on body segments using the equations of Gauld et al. 2. To analyze its applicability in the estimation and interpretation of body mass index (BMI). Materials and methods. A sample of children and adolescents without musculoskeletal alterations. Height, arm span, length of the ulna, the forearm, the tibia and the leg, weight, and pubertal development were registered. BMI was estimated. Differences and agreements between $\mathrm{OH}$ and $\mathrm{PH}$ were analyzed using the BlandAltman method and an intraclass correlation coefficient. For BMI, the absolute prediction error and agreement were estimated using a Kappa coefficient.

Results. Two hundred and twenty children and adolescents aged 6.04-19.1 years were included. The intraclass correlation coefficient between $\mathrm{PH}$ and $\mathrm{OH}$ was $>0.9$ in all equations. In average, $\mathrm{PH}$ overestimated OH by less than $2.0 \mathrm{~cm}$, except when using the ulna length $(2.6 \mathrm{~cm}$ among girls and $3.4 \mathrm{~cm}$ among boys). The average absolute prediction error for BMI was $<5 \%$, except for the ulna length, and the Kappa coefficient was $>0.7$. Conclusions. In oursample, theequations of Gauld et al. were adequate to predict height and estimate BMI. The greatest difference between observed height and predicted height was observed when using the ulna length.

Key words: result reproducibility, prediction, height, body segments, body mass index.

http: / / dx.doi.org/10.5546/ aap.2018.eng.xx

To cite: Ramos Mejía R, Caino S, Adamo P, Fano V, et al. Prediction of height and body mass index based on body segments. Use of Gauld's equations in an Argentine sample. Arch Argent Pediatr 2018;116(x):000-000.

\section{GLOSSARY}

BMI: body mass index.

CI: confidence interval.

ICC: intraclass correlation coefficient.

$\mathrm{OH}$ : observed height.

PH: predicted height.

SD: standard deviation.

SDS: standard deviation score

TEM: technical error of measurement.

\section{INTRODUCTION}

The measurement of height is one of the most commonly used anthropometric techniques in medical practice as an indicator of children's growth, nutritional status, and general health status. Knowing the height value is necessary to estimate various indices and indicators, such as body mass index (BMI), body surface area, drug dosage, blood pressure readings, and kidney or respiratory function.

Any tool used to assess growth aims at giving the most accurate and consistent measurements possible to minimize errors in result interpretation and any subsequent decision-making. ${ }^{1,2}$

Sometimes it is not possible to measure height directly using a stadiometer with the child standing or the measurement does not account for actual bone growth. Regarding this, in our hospital, it was not possible to measure height in $24 \%$ of hospitalized children due to pain, immobilization or drainage tubes, among other reasons. ${ }^{3}$

Height cannot be measured either in children or adolescents with neurological or muscle disease, myelomeningocele, joint contractures, spinal or chest deformity. 4,5 These children also require growth monitoring and nutritional status assessment, so height may 
be predicted based on body segments and subsequent BMI estimation.

Gauld et al. published equations to predict height based on the measurement of the arm span, the ulna, the forearm, the tibia, and the leg in a sample of healthy, Caucasian children and adolescents aged 5.3-19.5 years. ${ }^{4}$ These equations were used in some groups of patients with cerebral palsy, spinal muscular atrophy, and muscular dystrophy. ${ }^{6-11}$ However, the bibliography does not include studies on the reliability of height prediction using these equations in other populations or a history of its use in our setting. So we designed this study with the following objectives: 1 . to compare the value of observed height $(\mathrm{OH})$ and predicted height $(\mathrm{PH})$ using the equations of Gauld et al. in a sample of Argentine children and adolescents; 2. to analyze its applicability in the estimation and interpretation of BMI.

\section{POPULATION AND METHODS}

Children and adolescents aged 6.0-19.5 years who attended the outpatient offices of our hospital between July 2015 and July 2016 were included. This was a convenience sample, and participants were included in consecutive order until reaching at least 100 girls and 100 boys (50 who had achieved pubertal development and 50 without pubertal development in each group). The sample size was estimated following Altman's recommendations for method comparison studies. ${ }^{12}$

Children and adolescents with a short stature (less than -2.0 standard deviation score [SDS] for the Argentine population), ${ }^{13}$ a motor disability or physical conditions preventing them from standing correctly in the stadiometer, such as chest or spinal deformity, joint contractures, limb deformity, and neuromuscular disease, were excluded.

Participation was voluntary; caregivers gave their informed consent and minors, their assent, if applicable.

One single, trained observer measured, in a blinded and repeated manner, height, arm span, ulna length, forearm length, tibia length, leg length, and weight. This observer also did a physical examination to assess pubertal development and classified children into prepubertal and pubertal groups based on Tanner stages. $^{14}$

A second, trained observer took the same anthropometric measurements in 10 participants in order to estimate the inter-observer measurement error for each technique.

Body segments were measured using a Harpenden anthropometer; and arm span, with a specifically-designed millimeter graduated ruler; both instruments had a $1 \mathrm{~mm}$ precision. Body segments were measured in accordance with the recommendations of Gauld et al., which are detailed in Annex. ${ }^{15}$ Height was measured using a Seca stadiometer with a $1 \mathrm{~mm}$ precision and weight was obtained using a CAM beam scale with a $100 \mathrm{~g}$ precision, as per the Argentine Society of Pediatrics' recommendations. ${ }^{1}$

Before conducting the study, a pilot test was done to calibrate instruments, optimize measurement techniques, and provide related training.

The study was approved by the hospital's Associated Direction of Research and Teaching and the Ethics Committee (Protocol no. 886).

\section{Statistical analysis}

Step 1: Replicability and degree of consistency of each anthropometric technique

The intra- and inter-observer technical error of measurement (TEM) for each anthropometric technique was estimated as per the following formula: TEM $=\sqrt{\left[\sum \mathrm{d} 2 /(2 \mathrm{n})\right]}$, where $d$ is the difference between the first and second measurement and $n$, the number of cases. The relative TEM (percentage) was also estimated using the following formula: 100 * TEM $/ \bar{x}$, where $\bar{x}$ is the average of measurements. ${ }^{16,17}$ A relative TEM limit of $\leq 2 \%$ was accepted. ${ }^{16}$

\section{Step 2: Comparison between $\mathrm{OH}$ and $\mathrm{PH}$ using the equations of Gauld et al.}

Height was predicted using the equations of Gauld et al., ${ }^{4}$ as detailed in Table 1.

The sample was divided in two groups: boys and girls. Participants in each group were stratified into prepubertal and pubertal. The average of replicate measurements was considered for all analyses.

After confirming the normality of outcome measures using the Kolmogorov-Smirnov test, the differences and limits of agreement between $\mathrm{OH}$ and $\mathrm{PH}$ for each body segment and between $\mathrm{OH}$ and observed arm span were analyzed using the Bland-Altman method. This method, based on the quantification of agreement between two quantitative measurements, allows to estimate the mean, SD, and $95 \%$ confidence interval (CI) of the mean difference between two methods. ${ }^{18-20}$

In addition, as a measurement of agreement, 
the intraclass correlation coefficient (ICC) between $\mathrm{OH}$ and $\mathrm{PH}$ was estimated for each body segment. A value of $<0.5$ was considered poor agreement; between 0.5 and 0.75 , moderate agreement; between 0.75 and 0.9 , adequate agreement; and $>0.9$, excellent agreement. ${ }^{21}$

Step 3: Comparison between BMI estimated with $\mathrm{OH}$ and $\mathrm{PH}$ using the equations of Gauld et al.

The BMI -weight $(\mathrm{kg}) /$ height $^{2}(\mathrm{~m})$ - was estimated for each body segment.

The mean and SD of the absolute prediction error (APE) were estimated. The APE was calculated according to the following formula: $\mathrm{APE}=-\mathrm{I} 100$ * $(\mathrm{BMIOH}-\mathrm{BMIPH}) / \mathrm{BMIPHI}-$, where $\mathrm{BMIOH}$ corresponds to the $\mathrm{BMI}$ estimated using the $\mathrm{OH}$ and $\mathrm{BMIPH}$, the BMI estimated using the $\mathrm{PH}$ for each body segment. ${ }^{22}$

Then, absolute BMI values obtained using the $\mathrm{OH}$ and the $\mathrm{PH}$ were classified into two categories: normal or pathological, considering the criteria proposed by the World Health Organization (WHO) / National Center for Health Statistics (NCHS) in $2007,,^{23-25}$ and the degree of agreement was assessed using Cohen's Kappa coefficient. A value between 0.00 and 0.20 was considered poor agreement; between 0.21 and 0.40 , acceptable agreement; between 0.41 and 0.60 , moderate agreement; between 0.61 and 0.80 , adequate agreement; and between 0.81 and 1.00 , very adequate agreement. ${ }^{12,26}$

The MedCalc and SPSS software programs were used for statistical analysis.

\section{RESULTS}

Two hundred and twenty children and adolescents (114 girls) who met the inclusion criteria were included; their median age was
10.94 years (r: 6.04 to 19.30$) ; 105 / 220$ were stratified as prepubertal. The median height was 0.27 SDS (r: -1.93 to 1.99) and 0.34 SDS (r: -2.0-2.0) among girls and boys, respectively.

\section{Replicability and degree of consistency of each anthropometric technique}

The intra- and inter-observer TEM ranges were 0.13 to $0.17 \mathrm{~cm}$ and 0.29 to $0.54 \mathrm{~cm}$, respectively, for body segment measurement techniques. The intra- and inter-observer TEMs for height were $0.12 \mathrm{~cm}$ and $0.27 \mathrm{~cm}$, respectively.

The intra-observer relative TEM, which related the TEM to the average measured length, was 0.08 $\%, 0.15 \%, 0.35 \%, 0.38 \%, 0.51 \%$, and $0.76 \%$ for height, arm span, forearm length, leg length, tibia length, and ulna length, respectively. The ulna measurement technique showed an intra-observer relative TEM that was nine times higher than that corresponding to height. The inter-observer relative TEM for height was $0.17 \%$; for arm span, $0.26 \%$; for forearm, $0.72 \%$; for tibia, $0.91 \%$; for leg, $1.11 \%$; and for ulna, $1.47 \%$.

\section{Comparison between $\mathrm{OH}$ and $\mathrm{PH}$ using the equations of Gauld et al.}

Table 2 shows the average and SD of the differences between $\mathrm{OH}$ and $\mathrm{PH}$ for each body segment among prepubertal and pubertal girls and boys. The average of the differences between $\mathrm{OH}$ and $\mathrm{PH}$ was less than $1.2 \mathrm{~cm}$ among girls and less than 1.8 among boys, and the highest difference was when using the ulna length equation and in pubertal groups.

Figure 1, part A, shows the Bland-Altman plots for the differences between $\mathrm{OH}$ and $\mathrm{PH}$ for each equation. The $\mathrm{Y}$ axis shows the differences

TABLE 1. Equations proposed by Gauld et al. to predict height based on body segments ${ }^{4}$

\section{Girls}

PH obtained from arm span

PH obtained from ulna length

PH obtained from forearm length

PH obtained from tibia length

PH obtained from leg length

\section{Boys}

PH obtained from arm span

PH obtained from ulna length

PH obtained from forearm length

PH obtained from tibia length

PH obtained from leg length

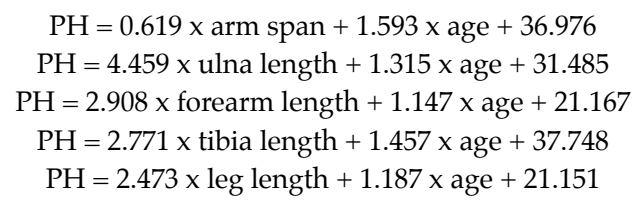

$\mathrm{PH}=0.619 \times$ arm span $+1.593 \times$ age +36.976

$\mathrm{PH}=4.459 \times$ ulna length $+1.315 \times$ age +31.485

$\mathrm{PH}=2.908 \times$ forearm length $+1.147 \times$ age +21.167

$\mathrm{PH}=2.771 \times$ tibia length $+1.457 \times$ age +37.748

$\mathrm{PH}=2.473 \times$ leg length $+1.187 \times$ age +21.151

PH: predicted height.

\author{
$\mathrm{PH}=0.829 \times$ arm span $+0.721 \times$ age +16.258 \\ $\mathrm{PH}=4.605 \times$ ulna length $+1.308 \times$ age +28.003 \\ $\mathrm{PH}=2.904 \times$ forearm length $+1.193 \times$ age +20.432 \\ $\mathrm{PH}=2.758 \times$ tibia length $+1.717 \times$ age +36.509 \\ $\mathrm{PH}=2.423 \times$ leg length $+1.327 \times$ age +21.818
}


in height between $\mathrm{OH}$ and $\mathrm{PH}$ for each body segment, and the $\mathrm{X}$ axis, the average $\mathrm{OH}$ and PH.PH significantly overestimated $\mathrm{OH}$ in all equations, except in the arm span equation (mean $p=0.052$ ) for boys and in the leg length equation (mean $p=0.145$ ) for girls. The observed average differences were independent from the child's height, except when using the ulna length $(p=0.001)$, forearm length $(p=0.02)$, and leg length $(p=0.001)$ in the boys group.

Part B of Figure 1 shows the differences between $\mathrm{OH}$ and observed arm span. The average differences between boys and girls with observed arm span varied significantly depending on the child's size $(p=0.001)$.

The ICC between $\mathrm{OH}$ and $\mathrm{PH}$ was $>0.9$ in both boys and girls for all equations, and a greater data dispersion was observed in pubertal groups.

\section{Comparison between BMI estimated with $\mathrm{OH}$ and $\mathrm{PH}$ using the equations of Gauld et al.}

A normal BMI was observed in $56.1 \%(64 / 114)$ of girls and $55.7 \%$ (59/106) of boys.

Table 3 shows the APE percentage for the BMI estimated with the $\mathrm{OH}$ and the $\mathrm{PH}$ for each body segment among prepubertal and pubertal girls and boys. The average APE percentage for the BMI was $<5 \%$ in both boys and girls, similar in all equations, and was higher when using the ulna length $(5.6 \%)$.

The percentage of cases that showed a change in the diagnostic nutritional status was $<10 \%$, except when using the ulna length in pubertal boys $(17 \%)$.

As shown in Table 4, the Kappa coefficient for the BMI diagnostic categories was $\geq 0.70$ in all equations and higher among boys and prepubertal girls.

TABLE 2. Difference between observed height and predicted height using the equations of Gauld et al.

\begin{tabular}{lccccc}
\hline & $\begin{array}{c}\text { OH-PH based on } \\
\text { arm span (cm) }\end{array}$ & $\begin{array}{c}\text { OH-PH based on } \\
\text { ulna (cm) }\end{array}$ & $\begin{array}{c}\text { OH-PH based on } \\
\text { forearm (cm) }\end{array}$ & $\begin{array}{c}\text { OH-PH based on } \\
\text { tibia (cm) }\end{array}$ & $\begin{array}{c}\text { OH-PH based on } \\
\text { leg (cm) }\end{array}$ \\
\hline & Mean (SD) & Mean (SD) & Mean (SD) & Mean (SD) & Mean (SD) \\
\hline Girls & & & & & \\
All $(\mathrm{n}=114)$ & $-1.04(3.28)$ & $-2.62(4.18)$ & $-1.14(3.27)$ & $-0.81(3.37)$ & $0.45(3.27)$ \\
Prepubertal ( $=50)$ & $-0.88(2.40)$ & $-2.01(3.27)$ & $-0.87(2.74)$ & $-0.77(2.54)$ & $0.75(3.00)$ \\
Pubertal $(\mathrm{n}=64)$ & $-1.18(3.85)$ & $-3.10(4.74)$ & $-1.35(3.65)$ & $-0.84(3.91)$ & $0.21(3.47)$ \\
Boys & & & & & \\
All (n=106) & $-0.52(2.75)$ & $-3.37(3.62)$ & $-1.77(3.05)$ & $-1.33(3.40)$ & $-0.01(3.17)$ \\
Prepubertal $(\mathrm{n}=55)$ & $-0.30(2.60)$ & $-2.38(2.90)$ & $-1.26(2.86)$ & $-1.03(2.74)$ & $0.87(2.98)$ \\
Pubertal $(\mathrm{n}=51)$ & $-0.76(2.91)$ & $-4.43(4.02)$ & $-2.32(3.17)$ & $-1.65(4.00)$ & $-0.96(3.13)$ \\
\hline
\end{tabular}

$\mathrm{OH}$ : observed height; PH: predicted height; SD: standard deviation.

TABLE 3. Absolute prediction error of body mass index estimated with the observed height and the predicted height using Gauld's equations

\begin{tabular}{|c|c|c|c|c|c|}
\hline & Arm span & Ulna & Forearm & Tibia & Leg \\
\hline \multicolumn{6}{|l|}{$\begin{array}{l}\text { Girls } \\
\% \text { of APE Mean (SD) }\end{array}$} \\
\hline All $(\mathrm{n}=114)$ & $3.77(2.96)$ & $5.37(4.54)$ & $3.76(3.04)$ & $3.93(2.70)$ & $3.68(2.73)$ \\
\hline Prepubertal $(\mathrm{n}=50)$ & $3.24(2.45)$ & $4.70(3.88)$ & $3.45(2.83)$ & $3.51(2.21)$ & $3.80(2.90)$ \\
\hline Pubertal $(n=64)$ & $4.18(3.27)$ & $5.89(4.96)$ & $4.0(3.20)$ & $4.26(3.00)$ & $3.59(2.61)$ \\
\hline \multicolumn{6}{|l|}{$\begin{array}{l}\text { Boys } \\
\% \text { of APE Mean (SD) }\end{array}$} \\
\hline All $(n=106)$ & $3.24(2.18)$ & $5.58(3.97)$ & $3.98(2.87)$ & $4.00(3.12)$ & $3.65(2.61)$ \\
\hline Prepubertal $(\mathrm{n}=55)$ & $3.26(2.30)$ & $4.73(3.41)$ & $3.85(2.82)$ & $3.59(2.57)$ & $3.89(2.76)$ \\
\hline Pubertal $(\mathrm{n}=51)$ & $3.22(2.06)$ & $6.49(4.34)$ & $4.11(2.94)$ & $4.45(3.59)$ & $3.40(2.45)$ \\
\hline
\end{tabular}

$\mathrm{APE}($ absolute prediction error $)=\mathrm{I} 100$ * $(\mathrm{BMIOH}-\mathrm{BMIPH}) / \mathrm{BMIPHI}$.

SD: standard deviation.

BMI: body mass index. 
Figure 1. Part A. Differences and limits of agreement between observed height and predicted height for each equation using the Bland-Altman method (cm)

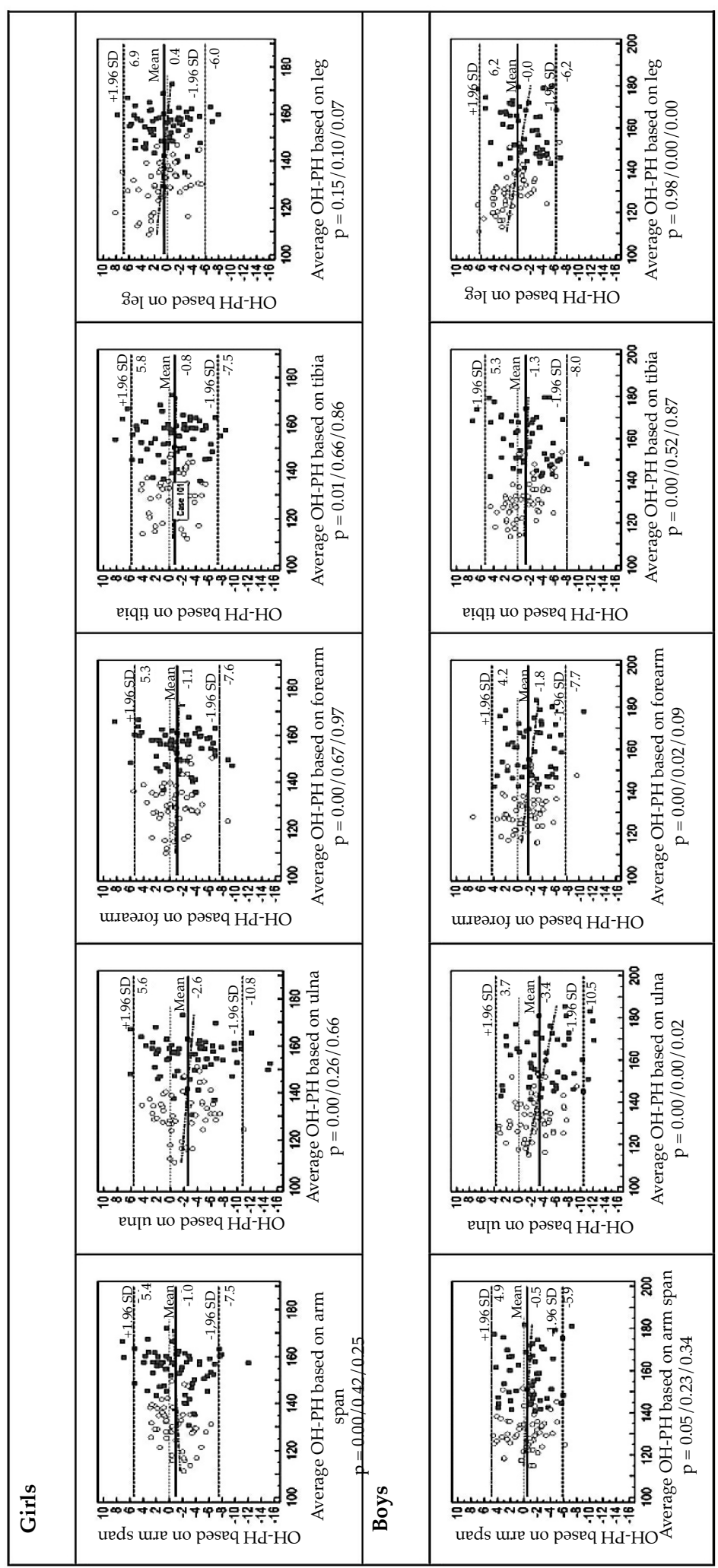

$\mathrm{OH}$ : observed height; $\mathrm{PH}$ : predicted height. Mean $\mathrm{p} /$ slope $\mathrm{p} /$ intercept $\mathrm{p}$.

The $\mathrm{Y}$ axis shows the differences between the $\mathrm{OH}$ and the $\mathrm{PH}$ in centimeters; the $\mathrm{X}$ axis shows the average $\mathrm{OH}$ and $\mathrm{PH}$ in centimeters. 
FIGURE 1. Part B. Differences and limits of agreement between observed height and observed arm span using the BlandAltman method (cm)

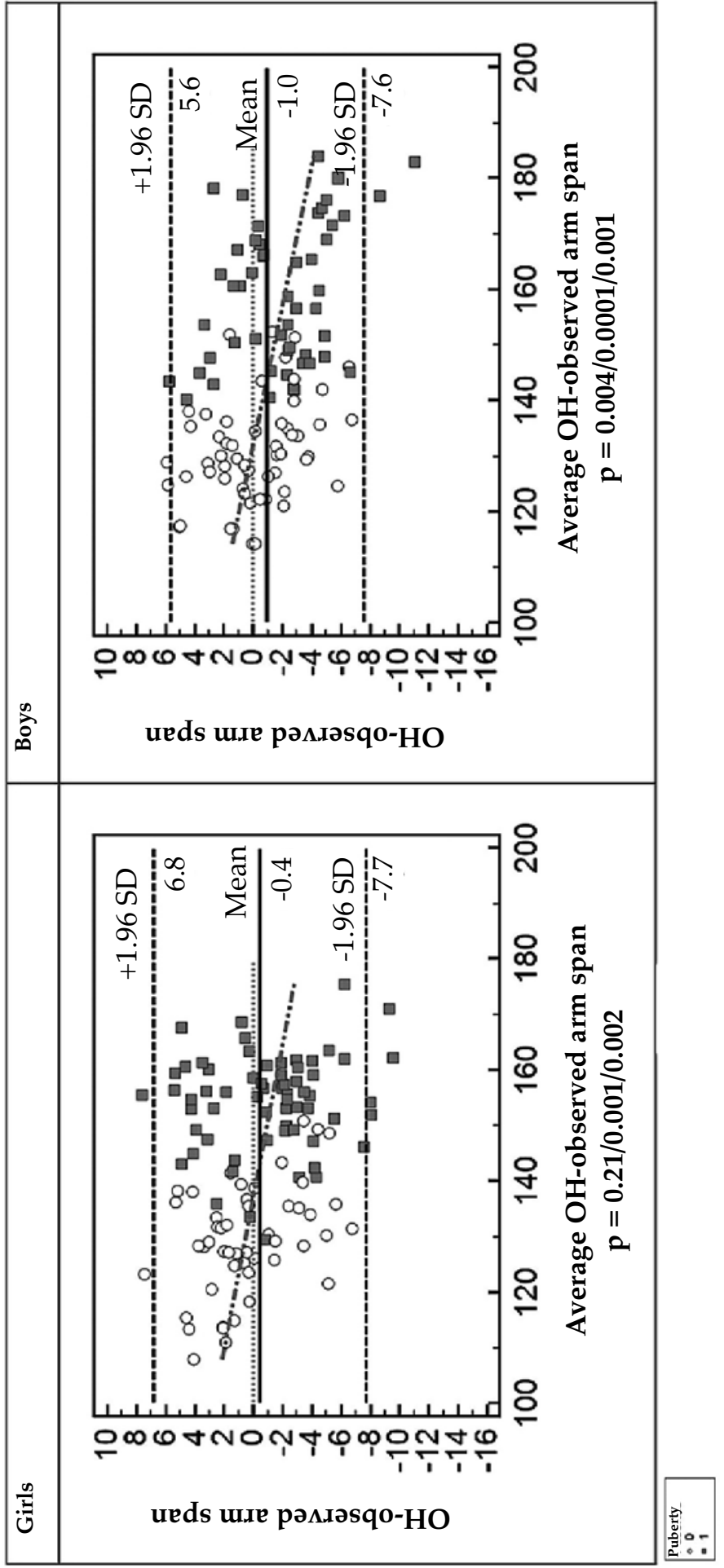

OH: observed height. Mean $\mathrm{p} /$ slope $\mathrm{p} /$ intercept $\mathrm{p}$.

The $\mathrm{Y}$ axis shows the differences between the $\mathrm{OH}$ and the observed arm span in centimeters; the $\mathrm{X}$ axis shows the average $\mathrm{OH}$ and observed arm span in centimeters. 


\section{DISCUSSION}

In our study, an excellent agreement was observed between $\mathrm{OH}$ and $\mathrm{PH}$ based on body segments, using the equations of Gauld et al. In average, $\mathrm{PH}$ overestimated $\mathrm{OH}$ by less than $2 \mathrm{~cm}$; these values were higher when using the ulna length equation and among pubertal groups. Such differences were smaller than those observed by Haapala et al., who described differences of up to $7.3 \mathrm{~cm}$ between $\mathrm{OH}$ and $\mathrm{PH}$ among children with cerebral palsy. ${ }^{8}$

In clinical practice, it is common to directly use the arm span value as an indicator of height; ${ }^{27-30}$ however, like Golshan et al., it has been noted that the average differences between observed arm span and height changed depending on the child's size. ${ }^{31}$ Given that height prediction using the studied equation showed a greater accuracy, it is recommended to use Gauld's equation to predict height based on arm span.

Anatomical landmarks were easily identified in body segment measurement techniques, and relative TEM was within the acceptable limits for the clinical assessment of growth. ${ }^{1,16}$ However, unlike what was proposed by Gauld et al., it was somehow difficult to locate the styloid process of the ulna in some children, especially those with overweight. Such difficulty was reflected in the higher intra-observer and inter-observer relative TEM compared to that obtained from other body segments and height measurement.

A strong agreement (Kappa coefficient $\geq 0.7$ ) was found between the diagnostic categories of BMI obtained with the $\mathrm{OH}$ and the $\mathrm{PH}$ using the equations of Gauld et al. However, and considering that in some participants the nutritional status diagnosis changed between the BMI estimated with the $\mathrm{OH}$ and that estimated with the $\mathrm{PH}$, we suggest to analyze how this indicator progresses over time instead of establishing a cross section.
The lower degree of agreement among BMI diagnostic categories when using the ulna length equation, as the greater difference between $\mathrm{OH}$ and $\mathrm{PH}$ using this body segment, may be associated with the greater difficulty in the measurement technique that is reflected in the higher relative TEM compared to other body segments. In this respect, we suggest that, in addition to training provided in advance to minimize measurement errors, the average of at least two replicate measurements should be used, and always use the same body segment during the longitudinal follow-up of a child or adolescent.

Body proportions change during puberty and, besides, the age of puberty onset varies among children. In this regard, it has been observed that the differences between $\mathrm{OH}$ and $\mathrm{PH}$ were higher; the ICC and the Kappa coefficient were lower in the pubertal group. Based on these findings, we propose that, in addition to age, sex, and body segment, pubertal development should be included as a correction factor in future equations to improve height prediction.

This is the first study that analyzes the reliability of the equations of Gauld et al. to predict height based on body segments, and its use to estimate BMI in a sample of Argentine children and adolescents without motor disability and with normal height for the reference population.

These equations were proposed for children and adults with different neuromuscular diseases, such as cerebral palsy, spinal muscular atrophy, and dystrophinopathies; ${ }^{6-11}$ therefore, in the future, it would be important to select the body segment that best predicts height in this population.

\section{CONCLUSIONS}

Based on our results, when height cannot be measured for various reasons, the equations of Gauld et al. are considered adequate to

TABLE 4. Agreement between diagnostic body mass index categories (normal, pathological) estimated based on observed height and predicted height. Kappa coefficient

\begin{tabular}{|c|c|c|c|c|c|}
\hline & Arm span & Ulna & Forearm & Tibia & Leg \\
\hline \multicolumn{6}{|l|}{ Girls } \\
\hline All $(n=114)$ & 0.77 & 0.70 & 0.77 & 0.79 & 0.75 \\
\hline Prepubertal $(n=50)$ & 0.88 & 0.84 & 0.88 & 0.88 & 0.88 \\
\hline Pubertal $(\mathrm{n}=64)$ & 0.68 & 0.59 & 0.69 & 0.72 & 0.65 \\
\hline \multicolumn{6}{|l|}{ Boys } \\
\hline All $(n=106)$ & 0.92 & 0.81 & 0.89 & 0.85 & 0.91 \\
\hline Prepubertal $(n=55)$ & 0.93 & 0.71 & 0.85 & 0.82 & 0.82 \\
\hline Pubertal $(n=51)$ & 0.92 & 0.92 & 0.92 & 0.88 & 1.00 \\
\hline
\end{tabular}


predict height and to estimate BMI. The greatest difference between $\mathrm{OH}$ and $\mathrm{PH}$ was observed when using ulna length.

\section{REFERENCES}

1. Comité Nacional de Crecimiento y Desarrollo. Sociedad Argentina de Pediatría. Guía para la evaluación del crecimiento físico. 2013. [Accessed on: June $8^{\text {th }}, 2018$ ]. Availableat:http:/ / www.sap.org.ar/docs/publicaciones / libro_verde_sap_2013.pdf.

2. World Health Organization Multicentre Growth Reference Study Group. WHO Child Growth Standards: Length/ height-for-age, weight-for-age, weight-for-length, weightfor-height and body mass index-for-age: Methods and development. Geneva: World Health Organization, 2006. [Accessed on: September $4^{\text {th }}$, 2017]. Available at: http:/ / www.who.int/childgrowth/standards/technical_report/ en/.

3. Spirito MF, CainoS, VezzaniC, etal.Uso dela antropometría para la evaluación nutricional en pacientes internados en un hospital pediátrico de alta complejidad: su aplicabilidad y limitaciones. Med Infant 2017; 24(1):8-13.

4. Gauld LM, Kappers J, Carlin JB, Robertson CF. Height prediction from ulna length. Dev Med Child Neurol2004; 46(7):475-80.

5. Forman MR, Zhu Y, Hernández LM, et al. Arm span and ulnar length are reliable and accurate estimates of recumbent length and height in a multiethnic population of infants and children under 6 years of age. J Nutr2014; 144(9):1480-7.

6. Bönnemann CG, Rutkowski A, Mercuri E, et al. $173^{\text {rd }}$ ENMC international workshop: Congenital muscular dystrophy outcome measures 5-7 March 2010, Naarden, The Netherlands. NeuromusculDisord 2011; 21(7):513-22.

7. McDonald CM, Henricson EK, Abresch RT, et al. The cooperative international neuromuscular research group duchenne natural history study-a longitudinal investigation in the era of glucocorticoid therapy: Design of protocol and the methods used. Muscle Nerve 2013; 48(1):32-54.

8. Haapala H, Peterson MD, Daunter A, Hurvitz EA. Agreement between actual height and estimated height using segmental limb lengths for individuals with cerebral palsy. Am J Phys Med Rehabil2015; 94(7):539-46.

9. Kaufmann P,McDermott MP, Darras BT, et al. Observational Study of Spinal Muscular Atrophy Type 2 and 3: functional Outcomes Over 1 Year. Arch Neurol2011; 68(6):779-86.

10. Meier T, Rummey $C$, Leinonen $M$, et al. Characterization of pulmonary function in 10-18 year old patients with Duchenne muscular dystrophy. NeuromusculDisord2017; 27(4):307-14.

11. Wood CL, Straub V, Guglieri M, et al. Short stature and pubertal delay in Duchenne muscular dystrophy. Arch Dis Child 2016; 101(1):101-6.

12. Altman DG. Methods comparison studies. In: Altman DG. Practical Statistics for Medical Research. Londres: Chapman \&May; 1991.p.396-409.
13. Lejarraga $\mathrm{H}$, del Pino $\mathrm{M}$, Fano V, et al. Referencias de peso y estatura desde el nacimiento hasta la madurez para niñas y niños argentinos: Incorporación de datos de la OMS de 0 a 2 años, recálculo de percentilos para obtención de valores LMS. Arch Argent Pediatr2009; 107(2):126-33.

14. Tanner JM. Growth at adolescence. 2nd ed. Oxford: Blackwell, 1962.

15. Gauld LM, Kappers J, Carlin JB, Robertson CF. Prediction of Childhood Pulmonary Function Using Ulna Length. Am J RespirCrit Care Med 2003; 168(7):804-9.

16. Norton K, Olds T (edt). Anthropometrica: A Textbook of Body Measurement for Sports and Health Courses. Sidney: UNSW Press, 1996.

17. Cameron N. The Methods of Auxological Anthropometry. In: Falkner F, Tanner JM. Human growth: A comprehensive treatise. 2nd ed. Londres: Plenum Press, 1986.p.3-43.

18. Altman DG, Bland JM. Measurement in Medicine: The Analysis of Method Comparison Studies. J R Stat Soc Series D Stat 1983; 32(3):307-17.

19. Altman DG, Bland JM. Statistical methods for assessing agreement between two methods of clinical measurement. Lancet 1986; 8(8476):307-10.

20. Giavarina D. Understanding Bland Altman analysis. Biochemia Med (Zagreb). 2015; 25(2):141-51.

21. Koo TK, Li MY. A Guideline of Selecting and Reporting Intraclass Correlation Coefficients for Reliability Research. J Chiropr Med 2016; 15(2):155-63.

22. Smith RJ. Rethinking Allometry. J Theor Biol. 1980;87(1):97111.

23. World Health Organization. Growth reference data for 5-19 years. [Accessed on: September $\left.4^{\text {th }}, 2017\right]$. Available at: http:/ / www.who.int/ growthref.

24. De Onis M, Lobstein T. Defining obesity risk status in the general childhood population: Which cut-offs should we use? Int J PediatrObes2010; 5(6):458-60.

25. Cole TJ, Flegal KM, Nicholls D, Jackson AA. Body mass index cut offs to define thinness in children and adolescents: international survey. BMJ 2007; 335(7612):194.

26. Landis JR, Koch GG. The Measurement of Observer Agreement for Categorical Data. Biometrics 1977;33(1):15974.

27. Aggarwal AN, Gupta D, Ezekiel LM, Jindal SK. Statistical estimation of height from arm Span in north indian subjects. Indian J PhysiolPharmacol2000; 44(3):329-34.

28. DattaBanik S. Arm span as a proxy measure for height and estimation of nutritional Status: a study among dhimals of darjeeling in West Bengal India. Ann Hum Biol2011; 38(6):728-35.

29. Zverev Y, Chisi J. Estimating height from arm span measurement in Malawian children. CollAntropol2005; 29(2):469-73.

30. Yousafzai AK, Filteau SM, Wirz SL, Cole TJ. Comparison of armspan, arm length and tibia length as predictors of actual height of disabled and nondisabled children in Dharavi, Mumbai, India. Eur J ClinNutr2003; 57(10):1230-4.

31. Golshan M, Amra B, Hoghoghi MA. Is arm span an accurate measure of height to predict pulmonary function parameters? Monaldi Arch Chest Dis 2003; 59(3):189-92. 


\section{ANNEX \\ Techniques to measure body segments}

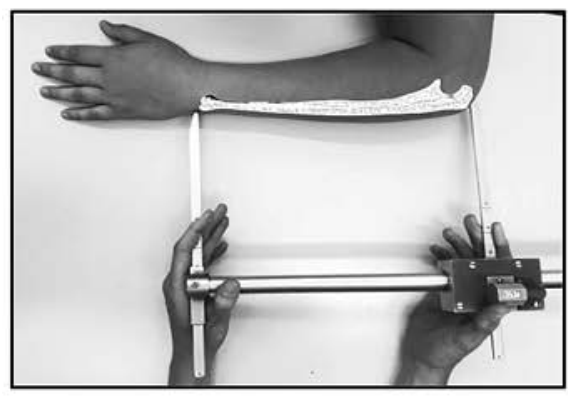

Ulna length

The ulna length was measured between the styloid process and the distal end of the elbow. The child was sitting down, with the left elbow flexed at $90-110^{\circ}$, the forearm resting on a table, the palm of the hand facing downward, and the fingers extended but together. ${ }^{15}$

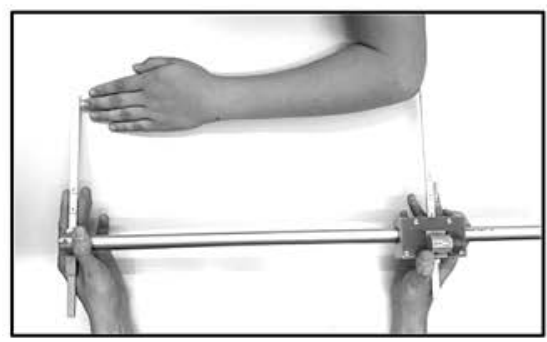

Forearm length

The forearm was measured between the distal end of the left middle finger and the elbow. The child was in the same position used to measure the ulna length. ${ }^{15}$

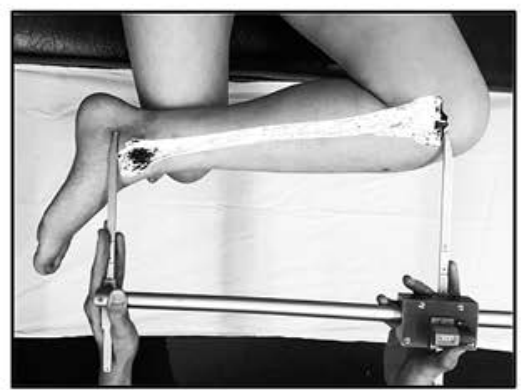

Tibia length

The tibia was measured between the internal tibial endplate and the most distal point of the medial malleolus. The child was sitting down with the left leg crossed over the right leg and the knee flexed. ${ }^{15}$

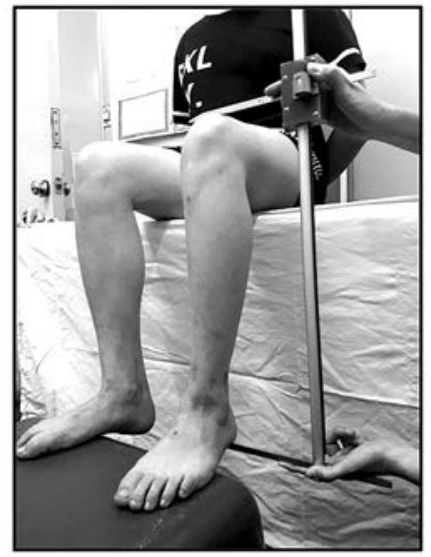

Leg length

The left leg length was measured between the upper side of the knee and the heel. The child was sitting down, with the knee flexed at $90^{\circ}$ at the level of the hip and the foot resting on a flat surface at $90^{\circ}$ in relation to the leg longitudinal axis. $^{15}$

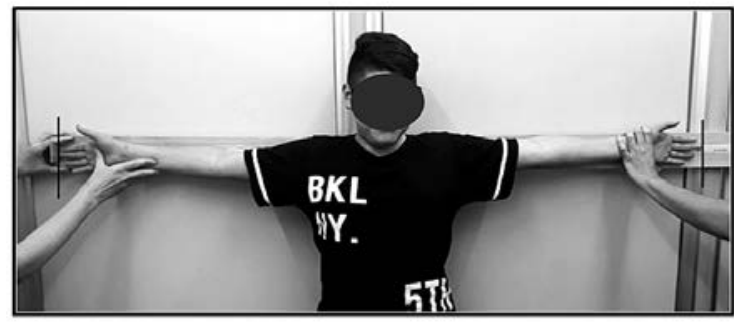

\section{Arm span}

The arm span is the distance between the top of the middle finger of a hand and that of the other hand. To measure it, the child was standing with the arms outstretched as far as they will go, perpendicular to the axial axis, and with the palms of the hands facing forward. ${ }^{15}$ 